Advances in Geosciences, 2, 151-155, 2005

SRef-ID: 1680-7359/adgeo/2005-2-151

European Geosciences Union

(c) 2005 Author(s). This work is licensed

under a Creative Commons License.

\title{
Sampling errors in rainfall measurements by weather radar
}

\author{
F. Piccolo ${ }^{1}$ and G. B. Chirico ${ }^{2}$ \\ ${ }^{1}$ Institute of Atmospheric Sciences and Climate, CNR, Rome, Italy \\ ${ }^{2}$ Department of Agricultural Engineering, University of Neaples Federico II, Italy
}

Received: 13 December 2004 - Revised: 15 April 2005 - Accepted: 18 April 2005 - Published: 13 May 2005

\begin{abstract}
Radar rainfall data are affected by several types of error. Beside the error in the measurement of the rainfall reflectivity and its transformation into rainfall intensity, random errors can be generated by the temporal spacing of the radar scans. The aim of this work is to analize the sensitivity of the estimated rainfall maps to the radar sampling interval, i.e. the time interval between two consecutive radar scans. This analysis has been performed employing data collected with a polarimetric C-band radar in Rome, Italy. The radar data consist of reflectivity maps with a sampling interval of $1 \mathrm{~min}$ and a spatial resolution of $300 \mathrm{~m}$, covering an area of $1296 \mathrm{~km}^{2}$. The transformation of the reflectivity maps in rainfall fields has been validated against rainfall data collected by a network of 14 raingauges distributed across the study area. Accumulated rainfall maps have been calculated for different spatial resolutions (from $300 \mathrm{~m}$ to $2400 \mathrm{~m}$ ) and different sampling intervals (from $1 \mathrm{~min}$ to $16 \mathrm{~min}$ ). The observed differences between the estimated rainfall maps are significant, showing that the sampling interval can be an important source of error in radar rainfall measurements.
\end{abstract}

\section{Introduction}

The meteorological radar is a very powerful and useful tool for hydrological applications, since it can provide estimates of rainfall fields with a high spatial and temporal resolution over large areas. After the NEXRAD weather radar network has been established in USA (Ogden and Julien, 1994), other countries have been investing significant resources for creating a weather radar network at national scale. Soon a large amount of radar rainfall data will be available for hydrological applications.

The weather radar emits electromagnetic pulsed radiation and it measures the backscattered echoes coming from the hydrometeors included in an elementary volume. The size

Correspondence to: F. Piccolo

(f.piccolo@isac.cnr.it) of this volume depends on the distance from the radar and it covers an area varying from a few hundred squared meters up to a few squared kilometres. The rainfall rate is estimated from the received echoes. A single radar is able to scan an area of hundreds of squared kilometres in a few seconds (Sauvageot, 1992).

However, the estimation of the rainfall from radar measurements is affected by different sources of errors ( $\mathrm{Za}-$ wadzki, 1984; Austin, 1987), which have to be well considered and quantified for a proper interpretation of the collected data. Radar errors can be grouped in three classes (Jordan, 2000).

The first class concerns with all those errors which can be removed by simply adjusting the radar reflectivity maps. This is the case of the errors due to ground clutters, anomalous propagation and beam blocking.

The second class concerns with all those systematic errors in the transformation of the radar reflectivity maps in rainfall maps, due for example to wrong radar calibration or contaminations in the reflectivity measurements induced by ice in the atmosphere. This kind of errors can be removed by improving the algorithms employed for transforming the reflectivity data and validating the results against raingauge data collected over long periods of time.

The third class concerns with random errors. This kind of errors can be generated, for example, by rainfall gradients within the sampling volume, a variability in the distribution of the hydrometeors within the elementary volume and sampling errors associated with the temporal spacing of the radar scans. The aim of this study is to evaluate the significance of the sampling error.

From a general point of view, the sampling error depends on the temporal and spatial scales of the measurement. The scale of the measurement can be defined by three factors, which can be applied to both the spatial and the temporal dimensions (Blöschl and Sivapalan, 1995): 1) the aggregation scale of the observation (support); 2) the interval between two contiguous observations (spacing); 3 ) the extent of the observation itself (extent). 


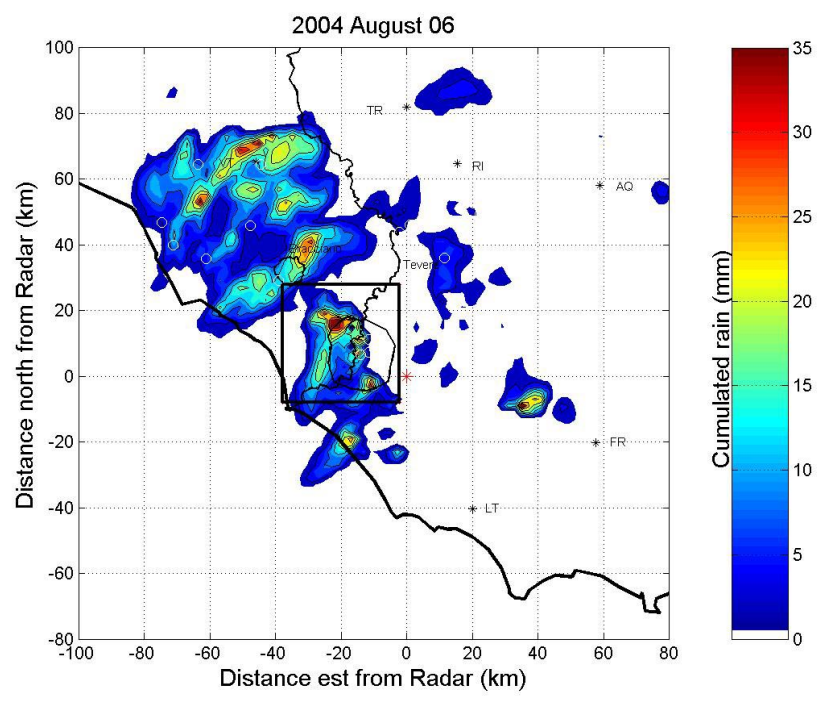

Fig. 1. Accumulated rainfall map of the storm event of the 6 August 2004. The coastline, the Tevere river and the Great Highway Belt of Rome are depicted. The red asterisk marks the radar position. The square highlights the area selected for this study.

In the case of a raingauge network, the observation of the precipitation field is characterised by a very small support (equal to the size of raingauge) and by a large spacing, equal to the distance between the raingauges. For this reason, raingauge data need to be interpolated in order to obtain continuous precipitation fields. On the other hand, the raingauge observations are continuous in time (null spacing in time) and are characterized by a very small temporal support (the automatic raingauges are able to provide rainfall data with a temporal resolutions of a few tens of seconds).

On the contrary, radar observations are characterized by a good spatial resolution (spacing and support in the radar measurements are equal to the target volume), but they are not continuous in time, since they are characterised by a temporal spacing which can be of several minutes. National radar networks, such as NEXRAD, are generally operated in order to provide volume scans with an interval of 5-10 $\mathrm{min}$ and a spatial resolution of $1 \mathrm{~km}$. For this reason, consecutive radar rainfields need to be interpolated in time in order to derive continuous precipitation fields. Usually this temporal interpolation is performed by assuming that the precipitation field is stationary within the sampling interval. However, this assumption can generate significant errors in the estimated precipitation fields, which can be interpreted as temporal sampling errors.

While the errors in the estimation of the instantaneous precipitation field have been extensively studied in literature (Zawadzki, 1984; Austin, 1987; Chandrasekar and Bringi, 1988; Gorgucci et al., 1996; Sharif et al., 2002; Krajewski and Smith, 2002), the errors due to the temporal sampling of the radar scans have been barely studied (Fabry et al., 1994).

The aim of this work is to illustrate the effect of the temporal spacing between the radar scans, using as case study
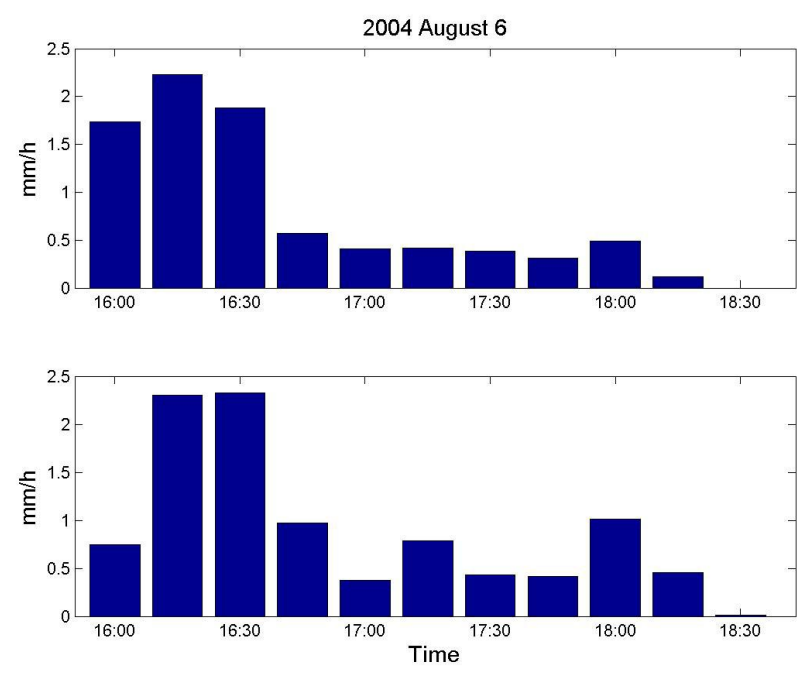

Fig. 2. Mean areal pluviographs with a temporal resolution of $15 \mathrm{~min}$, estimated respectively with the radar data (top panel) and the raingauge data (bottom panel).

the data collected during a summer storm monitored with a C-band radar in Rome.

\section{Experimental data}

The experimental data employed in this work have been collected with a C-band polarimetric radar, the POLAR 55C, located at the Institute of Atmospheric Science and Climate of National Research Council of Italy, $20 \mathrm{~km}$ far from centre of Rome. The radar has been specifically designed to obtain the polarimetric observables at a high quality level. The antenna consists of a $5 \mathrm{~m}$ off-set paraboloid, the azimuth beam width is 0.92 degree, without radome.

For this specific study, the radar has been operated in order to get reflectivity maps with the highest possible temporal and spatial resolution. The pulse repetition frequency has been set at $1200 \mathrm{~Hz}$, producing the maximum unambiguous range at the distance of $120 \mathrm{~km}$. The pulse duration has been set at $0.5 \mu \mathrm{s}$, the shortest possible, in order to get the highest possible spatial resolution, equal to $75 \mathrm{~m}$ in range. Radar scans have been performed at a single elevation angle (1.7 degree), such as a complete PPI could be acquired in just one minute.

The reflectivity data have been corrected for ground clutter contamination by a cascade of two filters (Giuli et al., 1991). The first filter has been derived by comparing reflectivity maps collected respectively during rainy and no-rainy periods. The second filter has been derived by analysing the standard deviation of the differential reflectivity. Then rainfall maps have been calculated by transforming the reflectivity maps with the classical equation:

$R=a Z^{b}$ 


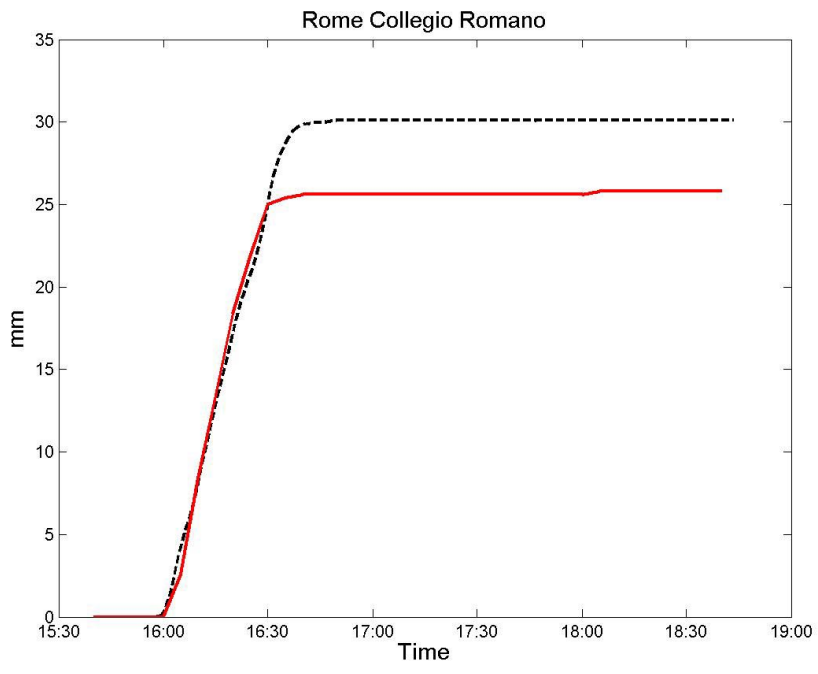

Fig. 3. Accumulated rainfall observed at the raingauge of Rome Collegio Romano (continuous line) and mean accumulated rainfall observed over a squared area of $4 \mathrm{~km}^{2}$ centred on the raingauge (dashed line).

where $R$ is the rain in $\mathrm{mm} / \mathrm{h}$ and $Z$ is the reflectivity factor $\left(\mathrm{mm}^{6} / \mathrm{m}^{3}\right)$. The parameters $a$ and $b$ have been set respectively to 0.1407 and 0.5413 , based on an optimization algorithm specifically developed for C-band radars (Gorgucci et al., 1998). The derived rainfall maps have been validated against rainfall data measured by 14 automatic raingauges distributed across the area, with a temporal resolution of 15 min.

After a long monitoring period, an interesting data set has been collected on the 6 August 2004, during an intense convective storm of three hours. The storm is characterised by high spatial and temporal variability. Figure 1 shows the accumulated rainfall map estimated with the POLAR 55C. Figure 2 compares the areal pluviographs estimated respectively with the raingauge network and the radar. The average rainfall volume is about $6 \mathrm{~mm}$, with local peaks higher than $30 \mathrm{~mm}$. In some points, the storm released the entire rainfall volume in half an hour (Fig. 3).

A squared area with side $36 \mathrm{~km}$ long, where rainfall data is available with an average spatial resolution of $300 \mathrm{~m}$, has been selected for this study. This area includes the entire urban area of Rome (Fig. 1).

The analysis performed on the selected dataset is illustrated in the following section.

\section{Experimental data analysis}

The selected dataset has been transformed into a series 170 squared grids of $120 \times 120$ pixels, representing on a Cartesian system the instantaneous precipitation fields with a spatial resolution of $300 \mathrm{~m}$ and a temporal interval of one minute.
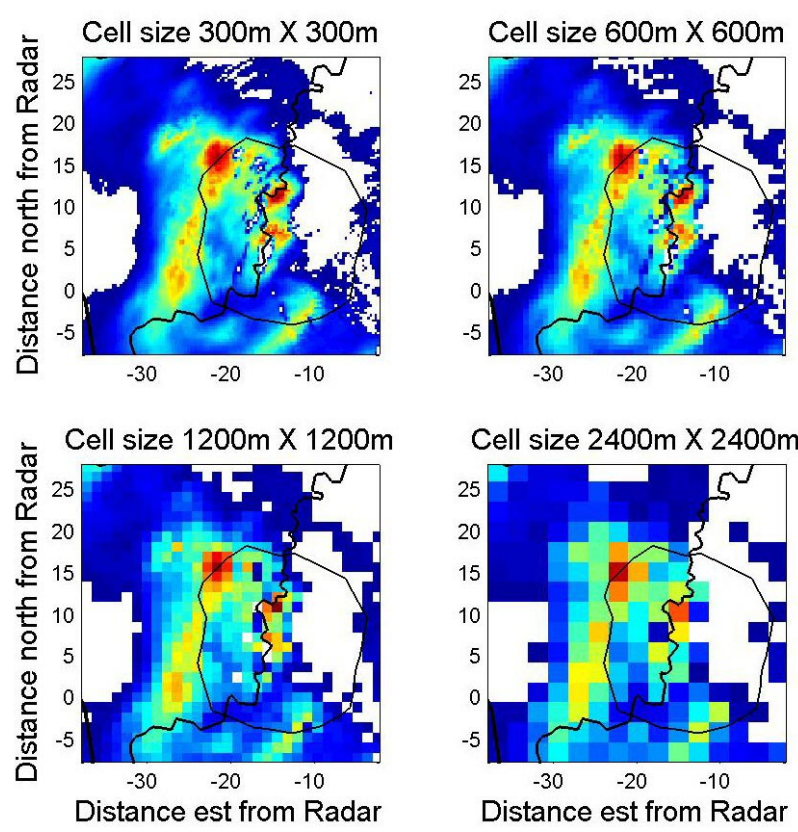

Fig. 4. Effect of the spatial aggregation on the accumulated rainfall maps.

These grids have been sampled in time and aggregated in space in order to evaluate the sensitivity of the estimated accumulated rainfall maps to the sampling temporal interval, for different spatial resolutions. The accumulated rainfall maps have been calculated by assuming the rainfall fields stationary within the sampling interval.

Rainfall grids have been sampled with 7 different sampling intervals, $\Delta t$, ranging from 2 to $16 \mathrm{~min}$. This set of sampling intervals covers the range of sampling intervals usually employed by operational radars. The sampled rainfall grids have been scaled by a factor, such as the total rainfall volume calculated across the entire selected area does not change with the sampling interval. The application of this scale factor is equivalent to adjusting the parameter $a$ of Eq. (1) after employing an optimization algorithm (Collier, 1996).

The rainfall grids have been also aggregated at three different spatial scales, respectively $600 \mathrm{~m}, 1200 \mathrm{~m}$ and $2400 \mathrm{~m}$, which are close to the typical spatial resolutions of operational radars. The effect of the spatial aggregation on the accumulated rainfall map is illustrated in Fig. 4.

The accumulated rainfall maps obtained for different sampling intervals have been compared to those obtained with a sampling interval of $1 \mathrm{~min}$ at different spatial scales of aggregation. The differences have been evaluated by the Normalized Standard Error (NSE), defined as:

$N S E(\Delta s, \Delta t)=\frac{1}{\bar{P}} \sqrt{\frac{\sum_{i=1}^{N_{\Delta S}}\left(P_{\Delta t \Delta s, i}-P_{\Delta s, i}^{*}\right)^{2}}{N_{\Delta s}}}$

where $\Delta s$ is the spatial scale of aggregation, $N_{\Delta s}$ is the number of pixels of side $\Delta s$ included in the selected area, $P_{\Delta t \Delta s, i}$ 


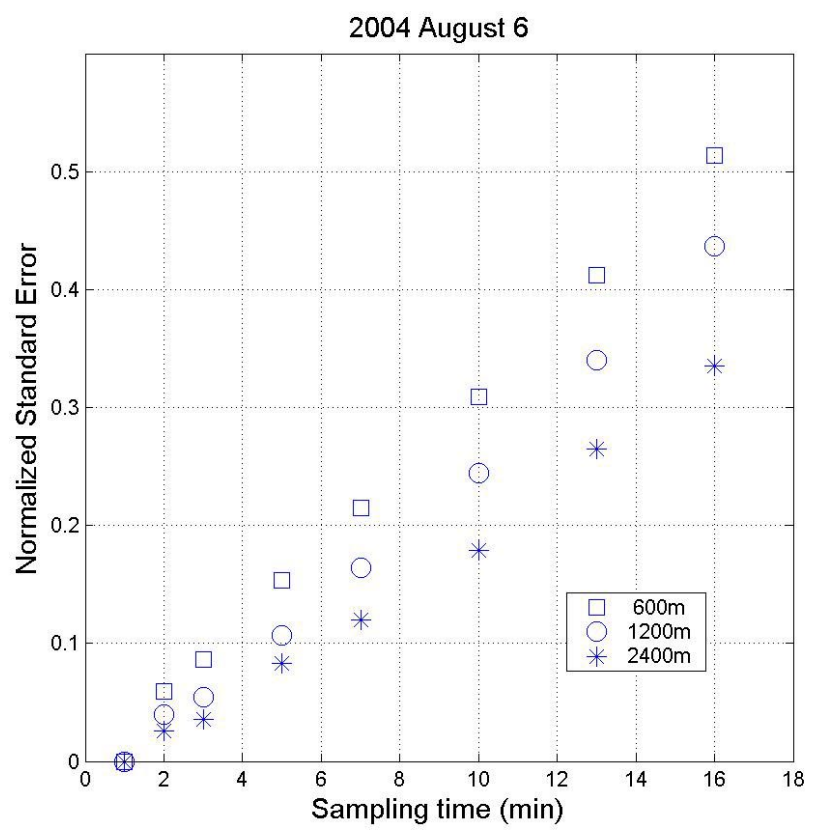

Fig. 5. Sensitivity of the Normalized Standard Error (NSE) to the radar sampling interval for different spatial aggregation scales.

is total rainfall volume computed over $i$-th pixel of side $\Delta s$ and with a sampling interval equal to $\Delta t, P_{\Delta s, i}^{*}$ is the rainfall volume computed over the same $i$-th pixel but with a sampling interval of $1 \mathrm{~min}, \bar{P}$ is the average rainfall volume computed across the entire selected area.

Figure 5 shows the calculated NSE values plotted versus the sampling interval for different spatial scales of aggregation. The NSE values obviously increase as the sampling interval increases, while they decrease as the scale of spatial aggregation increases. In particular for a sampling interval of $5 \mathrm{~min}$, the NSE values range from $10 \%$ to $15 \%$, while for a sampling interval of $10 \mathrm{~min}$ the NSE values range from $20 \%$ to $30 \%$. These error values are of the same order of magnitude of those generally ascribed to other sources of errors, such as systematic errors in the transformation of the radar reflectivity maps in rainfall maps (Brandes et al., 2002).

\section{Conclusions}

This study illustrated the effect of the temporal spacing of the radar scans on the estimated rainfall maps. The analysis was performed on C-band radar data collected with high spatial and temporal resolution during a summer storm in Rome. The specific aim of this work was to quantify the error that can be committed in the estimation of the accumulated rainfall map when the rainfall dynamics between two consecutive radar scans is not taken into account. The results show that the error in the estimated accumulated rainfall map can be significant even for sampling interval of 5-10 min, which are the sampling intervals usually employed in an operational context. Even though the results herein presented are based on data of a single storm event, this study highlights that the effect of the temporal spacing of the radar scans is not negligible, especially when radar data are employed to assess the rainfall volume over small catchments or for distributed model applications (Anagnostou et al., 2004; Dabbert et al., 2000). In order to reduce the effect of the temporal sampling, appropriate radar scan strategies should be designed. As an alternative, methods for effective temporal interpolation of consecutive reflectivity maps should be developed and applied.

Edited by: L. Ferraris

Reviewed by: anonymous referees

\section{References}

Anagnostou, E. N., Anagnostou, M. N., Krajewski, W. F., Kruger, A., and Miriovsky, B. J.: High-resolution rainfall estimation from X-Band polarimetric radar measurements, J. of Hydrometeorology, 5, 111-128, 2004.

Austin, P. M.: Relation between measured radar reflectivity and surface rainfall, Mon. Wea. Rev., 115, 1053-1070, 1987.

Blöschl, G. and Sivapalan, M.: Scale issues in hydrological modelling - a review, Hydrological Processes, 9, 251-290, 1995.

Brandes, E. A., Zhang, G., and Vivekanandan, J.: Experiments in rainfall estimation with a polarimetric radar in a subtropical environment, J. Appl. Meteor.,41, 674-685, 2002.

Chandrasekar, V. and Bringi, V. N.: Error structure of multiparameter radar and surface measurements of rainfall. Part I: Differential reflectivity, J. Atmos. Oceanic. Technol., 5, 783-802, 1988.

Collier, C. G.: Applications of weather radar systems: a guide to uses of radar data in meteorology and hydrology, Wiley, Chichester, 390 pp., 1996.

Dabbert, W., Hale, J., Krajewski, W. F., Crook, A., and Mueller, C.: Forecast issues in the urban zone: Report of the 10th prospectus development team of the U.S. Weather Research Program, Bull. Amer. Meteor. Soc., 81, 2047-2064, 2000.

Fabry, F., Bellon, M., Duncan R., and Austin G.: High resolution rainfall measurements by radar for very small basins: the sampling problem re-examined, J. Hydrol., 116, 415-428, 1994.

Giuli, D., Gherardinelli, M., Freni, A., Seliga, T. A., and Aydin, K.: Rainfall versus clutter discrimination by means of dual linear polarization measurements, J. Atmos. Oceanic Tech., 8, 777-789, 1991.

Gorgucci, E., Scarchilli, G., and Chandrasekar, V.: Error structure of radar rainfall measurement at C-band requencies with dualpolarization algorithm for attenuation correction, J. Geophys. Res., 101, 26461-26471, 1996.

Gorgucci, E., Scarchilli, G., and Chandrasekar, V.: Comparison of radar rainfall estimates and raingage measurements over the Central Apennines, Il Nuovo Cimento, 21C3, 265-279, 1998.

Jordan, P. W.: Effect on flood modelling of rainfall variability and radar rainfall measurement error, Ph.D. dissertation, Department of Civil Engineering, Monash University, Clayton, Victoria, Australia, 2000.

Krajewski, W. F. and Smith, J. A.: Radar hydrology: rainfall estimation, J. Adv. Water Res., 25, 1387-1394, 2002.

Ogden, F. L. and Julien, P. Y.: Runoff model sensitivity to radar rainfall resolution, J. Hydrol., 158 (1-2), 1-18, 1994. 
Sauvageot, H.: Radar Meteorology, Boston, MA, Artech House, 1992.

Sharif, H. O., Ogden, F. L., Krajewski, W. F., and Xue, M.: Numerical simulations of radar-rainfall error propagation, Water Resour. Res., 38, 8, 15-1-15-14, 2002.
Zawadzki, I.: Factors affecting the precision of radar measurements of rain. Preprints 22nd Radar Meteorology Conf., Zurich, Switzerland, Amer. Meteor. Soc., 251-256, 1984. 